\title{
Differences in blood pressure before and after administration of local anesthetic among obese adult female patients
}

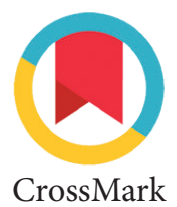

Ahyar Riza, ${ }^{*}$ Indra B. Siregar, Abdullah Oes, Tilagamalar*

Abstract

Objective: To determine the differences in blood pressure of female patients aged 26-45 years with normal Body Mass Index (BMI) and obesity after administration of local anesthetic containing adrenaline before dental extraction in the Department of Oral and Maxillofacial Surgery, Faculty of Dentistry, Universitas Sumatera Utara.

Material and Methods: This was an experimental study with a single group pretest-posttest design. Simple random sampling was used to select the subjects. 32 female patients aged 26-45 years participated in this study. 16 female patients with normal BMI and 16 female patients with obesity visited the clinic for dental extraction in the Department of Oral and Maxillofacial Surgery, Faculty of Dentistry, University of North Sumatera. Blood pressure of each subject was measured before and after administration of anesthesia. Data obtained was statistically analyzed using Dependent T-test.

Results: Systolic blood pressure between normal and obese subjects after administration of local anesthetic with adrenaline 1:80000 showed significant differences $(p<0.05)$. Diastolic blood pressure between normal and obese subjects after administration of local anesthetic with adrenaline 1:80000 showed no significant differences ( $p>0.05)$.

Conclusion: Administration of local anesthetic with adrenaline 1: 80000 can increase the blood pressure in obese patients and patients with normal BMI. Obese subjects are more prone to higher diastolic and systolic blood pressure changes compared to subjects with normal BMI.
Department of Oral and Maxillofacial Surgery, Faculty of Dentistry, University of North Sumatera, Medan, Indonesia

*Correspondence to: Ahyar Riza, Tilagamalar, Department of Oral and Maxillofacial Surgery, Faculty of Dentistry, University of North Sumatera, Medan, Indonesia ahyar.riza@usu.ac.id; malar.tilaga@yahoo.com

Received: 10 0ctober 2018 Revised: 8 November 2018 Accepted: 10 February 2019 Available Online: 1 April 2021

Keyword: Adrenaline, Blood pressure, Body mass index, Local anesthetic Cite this Article: Riza A, Siregar IB, Oes A, Tilagamalar. 2021. Differences in blood pressure before and after administration of local anesthetic among obese adult female patients. Journal of Dentomaxillofacial Science 6(1): 17-21. D0I: 10.15562/jdmfs.v6i1.830

\section{Introduction}

The 4 cardinal vital signs are blood pressure, heart rate, respiratory rate and body temperature. Blood pressure is capable in providing an overview of an individuals' cardiovascular status. Furthermore, measurement of the blood pressure is not only performed on patients with suspected hypertension but is also recommended for all patients in need of dental extraction. This examination could be used as a beneficial tool to prevent adverse events during or after invasive dental treatment. ${ }^{1,2}$

In the field of oral and maxillofacial surgery, use of local anesthesia often contain vasoconstrictors. ${ }^{3}$ Based on the study by Nakamura et al, significant increase in blood pressure and pulse rate during dental extraction was reported in cases where 2\% Lidocaine with epinephrine (1: 80.000) was administered as a local anesthetic. This study also showed that there was a strong correlation between dental extraction and blood pressure and proved that using epinephrine as an additional ingredient in anesthetic solutions had an effect on blood pressure. $^{4}$

Besides adrenaline in local anesthetics, an individuals' body weight could also be a causal factor in increasing blood pressure. Obesity is a symptom with abnormal or excessive fat accumulation in adipose tissues which result in severe systemic diseases. In general, obesity is a prime characteristic of hypertensive patients. The prevalence of obesity tends to increase with age, and reaches its peak in adulthood. ${ }^{5}$ According to the World Health Organization (WHO), the calculation of Body Mass Index (BMI) could be used as an important tool in measuring an individuals' weight based on his/her height. ${ }^{6}$

According to the report by National Health Survey of Indonesia (Riskesdas) in 2007 and 2010, the combined prevalence of overweight/obesity $\left(\mathrm{BMI}>25 \mathrm{~kg} / \mathrm{m}^{2}\right)$ in adults between ages $19-55$ years increased from $19.8 \%$ in 2007 to $23.0 \%$ in 2010 , with a higher predisposition in women $(24.6 \%$ and $28.7 \%$, respectively) compared to men (14.8\% and $17.0 \%$, respectively) in both years. ${ }^{7}$ The prevalence of obesity among men and women varies greatly within and between different countries. Women, in particular, have a higher predisposition of obesity that increases with age. These gender disparities are exacerbated among women in developing countries, particularly in the Middle East, North Africa and Indonesia. In middle-aged women, the biological factor and hormonal changes affects fat distribution that may increase risk or exacerbate detrimental 
effects of obesity on health. These biological and related socio-cultural differences warrant specific studies on women. ${ }^{8}$

Hence, the authors were interested to determine the differences in blood pressure of adult female patients with normal and obese Body Mass Index (BMI) after administration of local anesthetic containing adrenaline before dental extraction in the Department of Oral and Maxillofacial Surgery, Faculty of Dentistry, University of North Sumatera.

\section{Material and Methods}

This was an experimental study with a single group pretest-posttest design approach. Simple random sampling was used to select subjects for this research. The sample size was calculated using the paired numerical analytic formula. 32 female adult patients between the ages $26-45$, visited the Department of Oral and Maxillofacial Surgery, Faculty of Dentistry, University of North Sumatera for dental extraction. This study was conducted from 8 to 11 am in order to avoid circadian influences. ${ }^{9}$ The subjects eligible for this study were adult female patients, between the ages 26-45years, required either single mandibular premolar or molar extraction, in good health without any history of systemic diseases and medical allergies. Subjects that were excluded were those not interested to participate in this study. Drop out criteria were patients that were underweight. The subjects were divided into 2 groups; the control group which consisted of 16 female patients with normal Body Mass Index (BMI) and the case group composed of 16 female patients with obesity.

\section{Measurement of Height and Body Weight}

Verbal questioning regarding medical history was conducted to ensure the subjects were in good health and that they were not taking any medication which could possibly affect pain sensation and blood pressure. Height and weight of each subject was determined using the Body Mass Index (BMI). Body Mass Index (BMI) is a calculation of an individuals' weight in relation to his/her height. In this study, a BMI value of $18.5-22.9 \mathrm{~kg} / \mathrm{m}^{2}$ was considered normal while a BMI value of $>25.0 \mathrm{~kg} /$ $\mathrm{m}^{2}$ was categorized as obese. ${ }^{5}$ The height of subjects was measured using a measuring tape. The tape was secured to the wall and each subject was asked to stand erect against the tape without shoes, looking straight ahead. The height was then recorded in meters. The weight of the subjects was measured using a weighing scale. The subjects were asked one after the other to stand erect on the scale without shoes as well. The weight was then recorded in kilo-

\section{Treatment Protocol}

Patients were asked to sit and relax on the dental unit in a supine position for 5 minutes before beginning the procedure. Systolic and diastolic blood pressure was then measured using a Littman stethoscope and mercury sphygmomanometer on the patient's right arm parallel to the heart, 5 minutes before the administration of local anesthetic solution. ${ }^{11,12}$ Anesthetic solution used was Pehacain ${ }^{\circ}$ (PT. Phapros Tbk, Semarang, Indonesia) which contained 2\% lidocaine solution with adrenaline (1:80000). The anesthetic solution was administered through a mandibular block [conventional inferior alveolar nerve block (IANB)] and an estimated $1.0 \mathrm{ml}$ was deposited in the inferior alveolar nerve while $0.5 \mathrm{ml}$ was deposited in the lingual nerve. ${ }^{13}$ The procedure for administering local anesthetic was conducted by the faculty's clinical students with a minimum of 1 year experience. 5 minutes after administration of anesthesia, systolic and diastolic blood pressures were measured again and the data was recorded. Each measurement was carried out at least three times to obtain the average reading. Measurement of blood pressure was done by an intra-rater (measured by T.M. under supervision of A.R.). After administration of local anesthetic, the subjects in this study received dental extraction by the clinical students.

\section{Ethical considerations}

Before conducting this research, ethical clearance was approved by the Health Ethical Research Committee of University of North Sumatera (274/160518/KEPK FK USU-RSUP HAM/2018). In compliance with the Declaration of Helsinki, the consenting participants were informed that if they provided written informed consent, they would be included in this study.

\section{Statistical analysis}

Data processing was done using the Statistical Package for the Social Sciences version 17 (SPSS, Inc., Chicago, IL, USA) software and analyzed using Dependent T-Test. P values $<.05$ were considered statistically significant.

\section{Results}

The results for average systolic and diastolic blood pressure among normal and obese subjects showed increase in blood pressures before and after administration of anesthesia. However, obese patients were found to have a higher difference in systolic and diastolic blood pressure after administration of local anesthesia table 1.

The results of the difference in systolic blood pressure after administration of local anesthetics 
Table 1 Average systolic and diastolic blood pressures between normal and obese subjects before and after administration of local anesthesia

\begin{tabular}{|c|c|c|c|c|}
\hline Groups & $\mathbf{N}$ & Blood Pressure & Mean $(\mathrm{mm} \mathrm{Hg})$ & $\begin{array}{c}\text { Standard } \\
\text { deviation }( \pm)\end{array}$ \\
\hline \multirow{4}{*}{$\begin{array}{l}\text { Normal } \\
\text { BMI }\end{array}$} & \multirow[t]{4}{*}{16} & Systolic (Pre anesthesia) & 116.04 & 7.300 \\
\hline & & $\begin{array}{c}\text { Diastolic (Pre } \\
\text { anesthesia) }\end{array}$ & 71.67 & 5.018 \\
\hline & & $\begin{array}{l}\text { Systolic (Post } \\
\text { anesthesia) }\end{array}$ & 125.31 & 8.010 \\
\hline & & $\begin{array}{l}\text { Diastolic (Post } \\
\text { anesthesia) }\end{array}$ & 76.67 & 5.200 \\
\hline \multirow[t]{4}{*}{ Obese } & \multirow[t]{4}{*}{16} & Systolic (Pre anesthesia) & 116.67 & 6.885 \\
\hline & & $\begin{array}{c}\text { Diastolic (Pre } \\
\text { anesthesia) }\end{array}$ & 72.60 & 4.170 \\
\hline & & $\begin{array}{l}\text { Systolic (Post } \\
\text { anesthesia) }\end{array}$ & 133.02 & 4.952 \\
\hline & & $\begin{array}{l}\text { Diastolic (Post } \\
\text { anesthesia) }\end{array}$ & 79,90 & 1.771 \\
\hline
\end{tabular}

Table 2 Differences in systolic blood pressure post administration of local anesthetic with adrenaline

\begin{tabular}{llc}
\hline Group & $\mathbf{N}$ & Mean and Standard Deviation $\mathbf{( m m H g})$ \\
\hline Normal & 16 & $125.31 \pm 8.01$ \\
Obese & 16 & $133.02 \pm 4.95$ \\
\hline
\end{tabular}

Table 3 Differences in systolic pressure between the normal and obese groups using dependent T-test

\begin{tabular}{lc}
\hline Group & P Value (T-test) \\
\hline Normal & 0.003 \\
Obese & \\
\hline
\end{tabular}

Table 4 Differences in diastolic blood pressure post administration of local anesthetic with adrenaline

\begin{tabular}{llc}
\hline Group & $\mathbf{N}$ & Mean and Standard Deviation $(\mathbf{m m H g})$ \\
\hline Normal & 16 & $76.67 \pm 5.20$ \\
Obese & 16 & $79.90 \pm 1.77$ \\
\hline
\end{tabular}

Table 5 Differences in diastolic pressure between the normal and obese groups using dependent T-test

Group P Value (T-test)

Normal

Obese

0.0570

with adrenaline 1: 80000 on normal and obese patients showed that obese patients had higher systolic blood pressure compared to normal weighted patients table 2 .

The dependent T-test between both groups showed significant differences in systolic blood pressure between normal and obese patients $(\mathrm{p}=0.003)$ table 3 .

The results of the difference in diastolic blood pressure after administration of local anesthetics with adrenaline 1:80000 on normal and obese patients showed that obese patients had higher diastolic blood pressure compared to normal weighted patients table 4 .

The dependent $\mathrm{T}$ - test between both groups showed no significant differences in diastolic blood pressure between normal and obese patients $(\mathrm{p}=0.0570, \mathrm{p}>0.05)$ table 5 .

\section{Discussion}

Consistently across the studies, more women are obese than men. However, among young adults, more men are obese than women. By the late 20s, women had overtaken men in obesity; the cause of this is usually attributed to weight gain after pregnancy. This greater prevalence of overweight among men was especially true among Chinese but among Indians, more women are overweight compared to men. ${ }^{14}$ It appears that a similar finding was reported among Indonesian women where women are more prone to obesity than men. ${ }^{7}$ Furthermore, the gap between the prevalence of obesity between women and men had widened throughout the years.

The Joint National Committee on Prevention, Detection, Evaluation and Treatment of high blood pressure had classified blood pressure into four categories, namely; normal, pre-hypertension, stage-one hypertension, and stage-two hypertension. The normal category refers to blood pressure range of less than $120 / 80 \mathrm{mmHg}$, prehypertension is in the $120-139 / 80-89 \mathrm{mmHg}$ range, stage one is $140-159 / 90-99 \mathrm{mmHg}$ range and stage two is blood pressure equal to or greater than 160/100 $\mathrm{mmHg}$. Obese individuals have a 3.5- fold increased likelihood of having hypertension; $60 \%$ of hypertensive adults are $>20 \%$ overweight. It had been estimated that $60-70 \%$ of hypertension in adults may be directly attributable to adiposity. ${ }^{10,15}$ Despite reports from previous studies, ${ }^{5}$ we found that the initial blood pressure among female obese patients was within the normal range in this study. It is possible that despite having a high BMI, majority of the female subjects in this study had a higher socioeconomic status, hence they were more exposed to health information and be more likely than men to modify their unhealthy lifestyles. This could also explain their awareness on dental health and the importance of routine dental treatment. ${ }^{16}$

According to Managutti $\mathrm{A}$ et al., the use of $2 \%$ lidocaine with adrenaline 1: 80000 showed a signi- 
ficant increase in pulse rate and blood especially in systolic values. ${ }^{17}$ Using local anesthetics containing adrenaline showed a rise in systolic and diastolic pressure but only a small increment in blood pressure was reported, thus rendering this as clinically and medically irrelevant. ${ }^{18}$ The effect of adrenaline on beta 1 adregenic receptors in the heart stimulates the action of the heart by increasing contractile strength and conduction rate of the heart which can subsequently increase blood pressure greatly. ${ }^{19-21}$ On the other hand, it is known that pain during dental treatment may trigger release of endogenous catecholamine, which in turn can cause hemodynamic changes, such as increase in blood pressure and heart rate, and subsequently lead to arrhythmias. Few studies had reported significant increase $(5-12 \mathrm{mmHg})$ in systolic blood pressure in patients subjected to root scaling and planning using anesthesia with a vasoconstrictor. ${ }^{22}$

Patients that visit the dentist for the first time tend to fear dental extractions thus experiencing high levels of stress and anxiety. This situation may cause an increase in blood pressure and pulse rate. Anxiety is capable in causing changes within the body. It activates the endocrine system by stimulating the hypothalamus to secrete the Adrenocorticotropin Hormone (ACTH). ACTH will then activate the adrenal cortex to secrete cortisol. Cortisol plays a pivotal role in increasing blood pressure. A person that experiences anxiety would experience exponential increase in blood flow to the heart hence increasing cardiac pressure load. ${ }^{23}$

Generally, women are less susceptible to cardiovascular diseases including hypertension compared to men of the same age due to cardioprotective effects of estrogen. Estrogen provides a protective effect against cardiovascular diseases, which causes a decrease in Low Density Lipoprotein (LDL) and an increase in levels of High Density Lipoprotein (HDL) in blood plasma. ${ }^{24,25}$ In adult female patients with obesity, blood pressure showed a higher increase compared to adult female patients with normal BMI. Based on the Journal of Clinical Hypertension, Oparil stated that hormonal changes that often occurred in obese women causes them to be more likely to have high blood pressure. Obese women are also known to have higher blood pressure than men of the same age and this is often associated with female sex hormones such as estrogen. Estrogen is responsible for reducing arterial stiffness, endothelial dysfunction and accumulation of blood fats. In obese female patients, there is a continuous increase in adipose tissue formation. Estrogen levels in adipose tissue modulates Angiostenin II to activate the Renin-Angiotensin-Aldosterone system (SRAA). Increase in activation of SRAA can lead to an increase in blood pressure by inducing systemic vasoconstriction, sodium and water retention and an increase in aldosterone. ${ }^{24-27}$ Therefore, caution should be exercised in using local anesthetics containing vasoconstrictors in patients with obesity.

\section{Conclusion}

Despite the limitations in this study, it can be concluded that administration of local anesthetic lidocaine $2 \%$ with a combination of adrenaline 1: 80000 can increase the blood pressure of adult female patients with normal Body Mass Index (BMI) and obesity. There was a significant increase of systolic blood pressure in post administration of local anesthetic with adrenaline but as for diastolic blood pressure, there were no significant differences in post administration of local anesthetic with adrenaline.

\section{Acknowledgment}

The authors would like to express our appreciation to the University of North Sumatra for providing their fund for this research.

\section{Conflict of Interest}

The authors report no conflict of interest.

\section{References}

1. Malamed SF. Medical emergencies in the dental office. 6th ed. St.Louis; Mosby lsevier; 2007. p. 38-44

2. Sham EM, Rao SBH, Sultana N. Evaluation of cardiovascular changes in patients undergoing routine minor oral surgical procedure done under local anesthesia. Int $\mathrm{J}$ of Dent Clin 2012;4: 10-13.

3. Haas DA, Gaffen AS. Survey of local anesthetic use by ontario dentists. J Can Dent Assoc 2009;75: 649.

4. Nakamura Y, Matsumura K, Miura K, et al. Cardiovascular and sympathetic response to dental surgery with local anesthesia. Hypertens Res 2001;23: 209-214.

5. Dua S, Bhuker M, Sharma P, et al. Body mass index relates to blood pressure among adults. North American J Med Sci 2014;6: 89-95.

6. Romero-Corral A, Somers VK, Sierra-Johnson J, Thomas RJ, CollazoClavell ML, et al. Accuracy of body mass index in diagnosing obesity in the adult general population. Int J Obes 2008;32: 959-966.

7. Rachmi CN, Li M, Baur LLA. Overweight and obesity in Indonesia: prevalence and risk factors. Publ Health 2017;147: 20-29.

8. Ghorbani R, Nassaji M, Jandaghi J, et al. Overweight and obesity and associated risk factors among the Iranian middle-aged women. Int J Collab Res Intern Med Publ Health 2015;7: 120-131.

9. Nayak SB, Venkatesh D, Yogesh MK. Effect of obesity and hypertension on pulmonary functions. Natl J Physiol Pharm Pharmacol 2014:4: 47-50.

10. Igbokwe VU, Adebayo-Gege GI, Seriki AS. Prevalence of 
inter-arm blood pressure difference normal and hypertensive patients. J Cardiol Cardiovasc Ther 2017;7: 1-6.

11. Unsworth J, Tucker G, Hindmarsh Y. Man versus machine: the importance of manual blood pressure measurement skills amongst registered nurses. J Hosp Adm 2015;4: 61-67.

12. Bandl E, Boda K, Sonkodi S: Hypertension screening in a dental surgery: A Hungarian study. J Hum Hypertens 1990; 4: 253-257.

13. Thiem DGE, Schnaith F, Aken CMEV, et al. Extraction of mandibular premolars and molars: Comparison between local infiltration via pressure syringe and inferior alveolar nerve block anesthesia. Clin Oral Invest 2017;7: 1-9.

14. Gee LK. A review of adult obesity research in Malaysia. Med J Malaysia 2016;71: 1-19.

15. Chobanian AV, Bakris GL, Black HR, et al. The seventh report of the Joint National Committee on prevention, detection, evaluation, and treatment of high blood pressure: the JNC 7 report. JAMA 2003;289: 2560-2572.

16. Yu Z, Nissinen A, Vartiainen E, et al. Associations between socioeconomic status and cardiovascular risk factors in an urban population in China. Bull World Health Organiz 2000;78: 1296-305.

17. Managutti A, Prakasam M, Puthanakar N, et al. Comparative analysis of local anasthesia with 2 different concentrations of adrenaline: A randomized and single blind study. J Int Oral Health 2015;7: 24-27.

18. Ketabi M, Shamami MS, Alaie M. Influence of local anesthetics with or without epinephrine 1/80000 on blood pressure and heart rate. Dent Res J 2012;9: 437-440.

19. Balakrishnan R, Ebenezer V. Contraindications of vasoconstrictors in dentistry. Biomed and Phar J 2013;6: 409-414.
20. Fernandes SR, Castro NSR, Palma GMC, et al. Influence of vasoconstrictors added to dental anesthetics on blood pressure and heart rate. Rev Cubana de Estomatol 2017;54: 1-10.

21. Tsuchiya H. Dental anesthesia in the presence of inflammation: Pharmacological mechanisms for the reduced effi-cacy of local anesthetics. Int J Clin Anesthesiol 2016;4: 1059.

22. Silvestre FJ, Martinez IS, Bautista D, et al. Clinical study of hemodynamic changes during extraction in controlled hypertensive patients. Med Oral Patol Oral Cir Bucal 2011;16: e354- e358.

23. Duskova M, Vasakova J, Duskova J, et al. The role of stress hormones in dental management behavior problems. Physiol Res 2017;66: 317- 322.

24. Jiang SZ, Lu W, Zong XF, et al. Obesity and hypertension. Exp Ther Med 2016;12: 2395-2399.

25. Taylor LE, Sullivan JC. Sex differences in obesity-induced hypertension and vascular dysfunction: A protective role for estrogen in adipose tissue inflammation. Am J Physiol Regul Integr Comp Physiol 2016;311: 714-720.

26. DeMarco VG, Aroor AR, Sowers JR. The pathophysiology of hypertension in patients with obesity. Nat Rev Endocrinol 2014;10: 364-376.

27. Kaura AM, Bamgbose BO, Ogunwande SAB, et al. Effect of vasoconstrictor on arterial blood pressure during minor oral surgical procedures. J Dentomaxillofac Sci 2018; 3: 136-143.

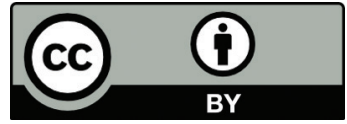

This work is licensed under a Creative Commons Attribution 